\title{
Predictors of Dental caries among children 7-14 years old in Northwest Ethiopia: a community based cross-sectional study
}

\author{
Fenta A Ayele ${ }^{1}$, Belaynew W Taye ${ }^{2}$, Tadesse A Ayele ${ }^{2}$ and Kassahun A Gelaye ${ }^{3^{*}}$
}

\begin{abstract}
Background: Dental caries in children remains a significant public health problem. It is a disease with multifactorial causes. The aim of the study was to assess the prevalence and associated factors of dental caries among children between 7 to 14 years old.

Methods: A community based cross-sectional study was conducted in Gondar town from June 2011 to September 2011. A total of 842 children were involved in the study. Multi-stage sampling technique was used to select the children. Pretested and structured questionnaires were used to collect data from mothers. Clinical examination of children was done using dental caries criteria set by world health organization. Data were entered, cleaned and edited using EPI Info version 3.5.1 and exported to SPSS version 16.0 for analysis. Binary multiple logistic regression analyses was applied to test the association.

Results: Four hundred sixty three (55\%) children were females. The prevalence of dental caries was 306(36.3\%).The educational status of children's father ( $A O R=0.3,95 \% \mathrm{Cl}, 0.17,0.80)$, monthly household income ( $\mathrm{AOR}=0.59,95 \% \mathrm{Cl}$, $0.01,0.45$ ), regular teeth brushing ( $A O R=0.08,95 \% \mathrm{Cl}, 0.03,0.20$ ) and using mouth rinsing ( $\mathrm{AOR}=0.40,95 \% \mathrm{Cl}, 0.2$, 0.80 ) were found statistically significantly associated with dental caries.

Conclusions: Dental caries were high among children in Gondar town. Low socioeconomic status and poor oral hygiene practices were the influencing factors for dental caries. Oral hygiene, dietary habits and access to dental care services are supreme important for the prevention of the problem.
\end{abstract}

Keywords: Dental caries, Mouth rinsing, Predictors, Northwest Ethiopia

\section{Background}

Dental caries are one of the public health problems in both developed and developing countries [1]. In developing countries, dental caries is increasing gradually due to the growing consumption of sugary substances, alcohol, substance abuse, cigarette smoking, poor oral care practices and inadequate health service utilization [2]. Dental caries result from dental plaque (bacteria) present in and around the teeth for long time. The frequent intake of sweets, dry mouth, and poor oral hygiene increase the chances for cavities [3]. The timing of the tooth eruption, the time span of the harmful dietary habit and the type of

\footnotetext{
* Correspondence: alemukass@yahoo.com

${ }^{3}$ Department of Environmental and Occupational Health and Safety, Institutes of Public Health, University of Gondar, P. O. Box 196, Gondar, Ethiopia

Full list of author information is available at the end of the article
}

muscle movements during sucking and swallowing are the common factors of dental caries. The early childhood caries pattern changes at age three and begins to affect the first and second primary molars $[4,5]$.

In Israel, 57\% immigrants had a "bad" health status of their teeth, $56 \%$ had gum problems, and $60 \%$ suffered from tooth ache [6]. The dental caries get increased with increasing age $[7,8]$. A study done in Northwest Ethiopia showed that the overall prevalence of dental caries was 47.1\% [9]. In Ethiopia, prevention and treatment of oral diseases receive little attention. Despite the fact that oral diseases are affecting majority of the Ethiopian children, much is not known about the extents and factors influencing the occurrence of dental caries and oral care practices and health care seeking behavior in most parts of the country particularly in the study area. This paper

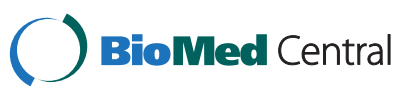


aimed to address this gap by attempting to identify predictors of dental caries and barriers to oral care practices. Therefore, the results of this paper may draw the attention to public health decision makers, ministry of health, nongovernmental organizations and other stake holders to revise their policies and programs.

\section{Methods}

A community based cross-sectional study was conducted from June 2011 to September 2011 to assess the prevalence and associated factors of dental caries among children at Gondar town. Gondar town is 737 kilometers away from the capital, Addis Ababa. According to 2011 Central Statistical Agency of Ethiopia (CSA) estimate, the town had a total population of 244,583 of whom children under 15 years of age were 104,192 [10]. The town has 12 urban and 12 rural kebele administrations. It has two government hospitals, seven health centers and 37 private clinics and one private hospital [11].

Children between 7 to 14 years of age and living in Gondar town were included in the study. Sample size was calculated using single population proportion formula with an assumption of 95\% confidence level, 5\% degree of precision, proportion of dental careis, $47.1 \%$ and design effect of two. Ten percent non- response rate was added to make the final sample size 842 . Multistage random sampling was employed to select the study subjects. Among twelve urban kebele administrations six kebele were selected randomly and then 62 'ketenas', the lowest administration, were selected using simple random sampling technique from each kebele. The sample size was allocated proportionally according to the size of children in each 'ketena'. Number of children and their name lists were taken from health posts and then children were selected randomly.

Pretested and structured questionnaires that included socio-demographic characteristics, dietary habit, health care seeking behavior towards oral health problems and oral care practice were used for data collection. The aim of the pretest was to increase the validity and reliability of data collection tools. Hence, data collection tools were pretested in other area which had a similar setup of the study area ahead of the actual data collection. After the pretest, we did amendments on the final version questionnaire based on the feedback we obtained from the pretest. Dental examination was carried out to all randomly selected children by dental doctors to identify the presence of dental caries cases. The dental examination was done in day light. Disposable wooden spatulas were utilized to check the presence of decay.

Trained six data collectors for data collection and three dental doctors for physical examination were involved. Prior to the study, data collectors were given two days intensive training on dental caries assessment based on
Table 1 Socio-demographic characteristics of children and their parents at Gondar town, Northwest Ethiopia, September 2011

\begin{tabular}{|c|c|c|}
\hline Variables & Frequency & Percentage \\
\hline \multicolumn{3}{|l|}{ Age } \\
\hline $7-10$ & 507 & 60.2 \\
\hline $11-14$ & 335 & 39.8 \\
\hline \multicolumn{3}{|l|}{ Sex } \\
\hline Male & 379 & 45 \\
\hline Female & 463 & 55 \\
\hline \multicolumn{3}{|l|}{ Ethnicity } \\
\hline Amhara & 727 & 86.3 \\
\hline Tigrie & 73 & 8.7 \\
\hline Other & 42 & 5 \\
\hline \multicolumn{3}{|l|}{ Religion } \\
\hline Orthodox & 692 & 82.2 \\
\hline Muslim & 119 & 14.1 \\
\hline Protestant & 13 & 1.5 \\
\hline Catholic & 11 & 1.3 \\
\hline Other & 7 & 0.8 \\
\hline \multicolumn{3}{|c|}{ Marital status of parents } \\
\hline Married & 559 & 66.4 \\
\hline Single & 25 & 3.0 \\
\hline Divorced & 142 & 16.9 \\
\hline Widowed & 116 & 13.8 \\
\hline \multicolumn{3}{|c|}{ Educational status of mother } \\
\hline Illiterate & 234 & 27.8 \\
\hline Can read and write & 51 & 6.1 \\
\hline $1-6$ grade & 155 & 18.4 \\
\hline $7-12$ grade & 273 & 32.4 \\
\hline$>12$ grade & 129 & 15.3 \\
\hline \multicolumn{3}{|c|}{ Educational status of father } \\
\hline Illiterate & 112 & 13.3 \\
\hline Can read and write & 94 & 11.2 \\
\hline 1-6 grade & 125 & 14.8 \\
\hline $7-12$ grade & 243 & 28.9 \\
\hline$>12$ grade & 268 & 31.8 \\
\hline \multicolumn{3}{|c|}{ Educational status of child } \\
\hline $0-4$ & 593 & 70.4 \\
\hline $5-8$ & 249 & 29.6 \\
\hline \multicolumn{3}{|c|}{ Monthly Income (US dollar) } \\
\hline$<27$ & 363 & 43.1 \\
\hline $28-56$ & 239 & 28.4 \\
\hline $57-84$ & 66 & 7.8 \\
\hline $85-112$ & 93 & 11.0 \\
\hline $113-167$ & 46 & 5.5 \\
\hline$>168$ & 35 & 4.2 \\
\hline
\end{tabular}


world health organization (WHO). The dental caries diagnosis protocol was obtained from WHO dental caries diagnosis guideline. The dentists or dental doctors were trained and practiced on pretest to follow and keep up uniform and standard dental caries assessment on children.

Caries was recorded as being present when a lesion in a pit or fissure or on smooth tooth surface had a detectable softened floor, undermined enamel or softened wall. A filled tooth also included in this category when it contains one or more restorations and one or more areas that are decayed. When any doubt existed, caries was not recorded as present. Tooth was considered missing because of caries if a person gave a history of pain and/or presence of cavity prior to extraction. Incomplete questionnaires were refilled during field work. Data were entered, cleaned and edited in EPI Info version 3.5.1 and exported to SPSS for windows version 16.0 for further analysis. Bivariate and multivariate analyses were employed. Odds ratio with $95 \% \mathrm{CI}$ was computed to assess the presence and degree of association between dependent and independent variables. A p-value $\leq 0.05$ was considered statistically significant in this study.

Ethical clearance was obtained from University of Gondar College of medicine and health sciences institutional review board. Official communication was made between Gondar city mayors. A written consent was obtained from parents before interview and examination. The data were collected anonymously. Cases of dental caries were referred to University of Gondar referral hospital dental clinic for treatment.

\section{Results}

A total of 842 study subjects were included in the study. Four hundred sixty three, (55\%) were females. Five hundred seven $(60.2 \%)$ of the children were in the age group of 7 to 10 years. The mean $( \pm$ SD) age of the children was $10.05( \pm 2.12)$ years. The majority, $727(86.3 \%)$ of children, were Amhara in ethnicity and 692(82.2\% were Orthodox Christian in religion.

Two hundred seventy three (32.4\%) mothers attained grades 7 to 12 and $268(31.8 \%)$ of fathers were above grade 12 in their educational status. The majority, 593 (70.4\%) of children were in first cycle education. Three hundred sixty three (43.1\%) families earned below 27 US Dollar per month (Table 1).

Food consumption pattern and dietary habits of children More than half, 462(54.9\%), of the children had three times meal schedule per day. Six hundred thirty six, (75.5\%) had breakfast bread with tea, 799(94.9) had lunch injera with sauces and 524 (62.2\%) ate snacks three times per day. Seven hundred thirty nine (87.8\%) of the subjects drunk tea with sugar, 478 (56.8\%) of the children used to drink soft drinks and $722(85.7 \%)$ used to consume sweet foods and drinks. Among the sweet food consumers, 199 (23.6\%) took daily (Table 2).

\section{Health seeking behaviors of parents and practices of dental care}

About 284(33.7\%) of parents/care takers accepted that their children had problem of dental caries. Only one

Table 2 Food consumption pattern and dietary habits of children aged between 7-14 years, Gondar town, North West Ethiopia, September 2011

\begin{tabular}{|c|c|c|}
\hline Variables & Frequency & Percent \\
\hline \multicolumn{3}{|l|}{ Frequency of meal } \\
\hline Once per day & 5 & 0.6 \\
\hline Twice per day & 43 & 5.1 \\
\hline Three times per day & 462 & 54.9 \\
\hline Four times and above & 332 & 39.4 \\
\hline \multicolumn{3}{|c|}{ Type of food for breakfast } \\
\hline Bread with tea & 636 & 75.5 \\
\hline Bread with milk & 45 & 5.3 \\
\hline Injera with wot & 140 & 16.6 \\
\hline Kinche & 21 & 2.5 \\
\hline \multicolumn{3}{|l|}{ Type of food for lunch } \\
\hline Bread with tea and milk & 22 & 2.6 \\
\hline Injera with wot & 799 & 94.8 \\
\hline Kinche and pourage & 21 & 2.6 \\
\hline \multicolumn{3}{|l|}{ Snack frequency } \\
\hline Three times per day & 524 & 62.2 \\
\hline Twice per day & 34 & 4.0 \\
\hline Once per day & 197 & 23.4 \\
\hline Occasional & 87 & 10.3 \\
\hline \multicolumn{3}{|c|}{ Consumption of sugared tea } \\
\hline Yes & 739 & 87.8 \\
\hline No & 103 & 12.2 \\
\hline \multicolumn{3}{|c|}{ Consumption of sugared coffee } \\
\hline Yes & 95 & 11.3 \\
\hline No & 747 & 88.7 \\
\hline \multicolumn{3}{|c|}{ Consumption of soft drinks } \\
\hline Yes & 478 & 56.8 \\
\hline No & 364 & 43.2 \\
\hline \multicolumn{3}{|c|}{ Consumption of sweet foods and drinks } \\
\hline Yes & 722 & 85.7 \\
\hline No & 120 & 14.3 \\
\hline \multicolumn{3}{|c|}{ Frequency of sweet foods and drinks } \\
\hline Daily & 199 & 23.6 \\
\hline Once per week & 74 & 8.8 \\
\hline Occasionally & 449 & 53.3 \\
\hline
\end{tabular}


hundred ninety one (67.3\%) of parents/care takers took their children to health institutions for medical help.

Four hundred seventy seven (56.7\%) children brushed their teeth, among these $189(38.8 \%)$ of the children brushed their teeth daily. Lack of knowledge 231 (63.3\%), time 44(12.15) and money 49(13.4\%) were the common reasons for not their children brushed their teeth (Figure 1).

\section{Dental caries}

All types of decayed teeth were identified in 306(36.3\%) children and the majority, 53(6.3\%) had incisors total decayed. All types of missed teeth were present in 135 (16.0\%) children and molar total missed were the largest 44(33.33\%) found in children. No filled cases were reported at all (Table 3$)$.

\section{Factors associated with dental caries problem among children}

There was statistically significant association between dental caries and educational status of the father $(\mathrm{AOR}=0.37,95 \% \mathrm{CI}, 0.17,0.80)$. Dental caries among children whose father were above grade 12 were $63 \%$ times at a lower risk compared to illiterates. Dental caries were lower among families of children who earned greater than 168 US Dollar per month as compared to those earn less than 27 US Dollar per month $(A O R=0.006$, $95 \% \mathrm{CI}, 0.074,0.47)$. Children who had cleaned their teeth were $99.4 \%$ times less likely to have caries as compared to those who did not clean (AOR $=0.078,95 \% \mathrm{CI}, 0.03-0.20$ ). The odds of having dental caries was also lower in children who have been rinsing their mouth after meal as compared to those who do not rinse $(A O R=0.399,95 \%$ CI,0.198,0.804) (Table 4).
Table 3 Dental cases of Gondar town children aged 7-14 years, North West Ethiopia, September 2011

\begin{tabular}{lcc}
\hline Characteristics & Frequency & Percent \\
\hline Decayed teeth (all types) & 306 & \\
Yes & 536 & 36.3 \\
No & 53 & 63.7 \\
Incisors total decayed & 44 & 17.3 \\
Canines total decayed & 105 & 14.4 \\
premolars total decayed & 172 & 34.3 \\
Molar total decayed & & 56.2 \\
Missed teeth (all types) & 135 & \\
Yes & 707 & 16.0 \\
No & 18 & 86.0 \\
Incisors missed & 32 & 13.3 \\
Canines missed & 41 & 23.7 \\
Premolars missed & 44 & 30.4 \\
Molars missed & & 33.3 \\
Place of Treatment & 192 & \\
Health Institute & 16 & 67 \\
Pharmacy & 12 & 6 \\
Traditional & 65 & 43 \\
Don't go anywhere & &
\end{tabular}

\section{Discussion}

The trends of dental caries in developing countries are gradually increasing. This study attempted to assess the prevalence and associated factors of dental caries among 7-14 years old children in Gondar town. The prevalence of dental caries found in this study was higher than a cohort of Ethiopian immigrants to Israel [6]. However, it was lower than a study done in kimer Dengay, Ethiopia

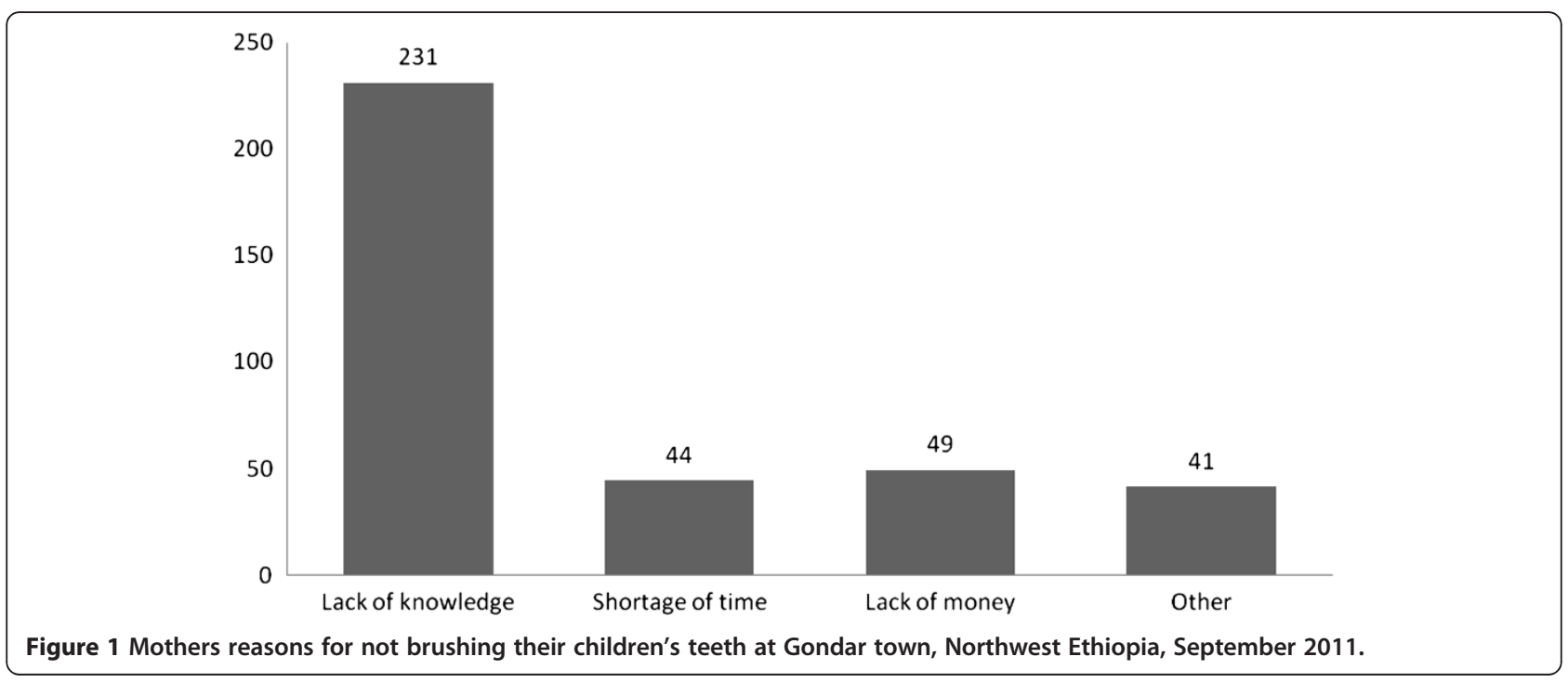


[9]. The difference in the later could be due to difference in access to awareness on oral hygiene as this study was undertaken in urban setting.

In this study, educational status of children's father was found to be statistical significant in different levels of dental carries. Hence, as education level of the father increases the probability of dental caries get reduced. This finding was also supported by similar findings [12-14]. There was also significant difference between monthly income of the households and dental caries. As income of the families increasing, children are less likely to be affected by dental decays. This could be elaborated that those who have better monthly income can have potential to buy tooth cleaning materials and well awarded for changes and have better health care seeking behavior. Similarly studies revealed that low monthly income were found to be more affected by teeth decays $[14,15]$.

This study revealed a strong positive association between caries development and tooth brushing practices. The more frequent brushing is performed the less caries children experiences [13]. Study done in Brazil also stated that children who started oral hygiene earlier presented with a lower prevalence of early childhood dental caries [15].

Mouth rinsing was significantly associated with caries. Individuals that rinse their mouth with water after meal were less likely to be attacked by dental caries than those who did not rinse. This could be due to the washing away of sugary food substances from the teeth; therefore, micro-organisms cannot get enough time for multiplication and growth and no acid production that causes caries development [16].

Molars decayed and premolars were the most frequently affected teeth by dental caries. The reason could be majority of the food was grinded with these teeth and both of them have very large surface area in which the food particles accumulated and harbor micro-organisms to proliferate. As a result, these acid producing bacteria might affect the enamel of the tooth which later went into decayed teeth. On the other hand the canines and incisors had the lowest decayed percentage among the four types of teeth. This could be explained by the fact that both of them are protected from direct exposure to acidic food by the tongue and less chance chewing food materials, also they are close to the sublingual salivary gland duct where it helps in diluting the acidic environment around the lower incisors.

Dental caries cases were identified only with clinical diagnosis, difficulty of radiological examination at field level might reduce the actual magnitude of the problem. Sweet food items and drinks were assessed by the usual patterns and/frequency of intake but the amount and the duration of intake was not well assessed.
Table 4 Factors associated with dental caries among children aged 7-14 years at Gonda town, Northwest Ethiopia, September 2011

\begin{tabular}{|c|c|c|c|c|}
\hline \multirow[t]{2}{*}{ Characteristics } & \multicolumn{2}{|c|}{$\begin{array}{l}\text { Decayed } \\
\text { teeth }\end{array}$} & \multirow[t]{2}{*}{ COR ( $95 \% \mathrm{Cl})$} & \multirow[t]{2}{*}{ AOR ( $95 \% \mathrm{Cl})$} \\
\hline & Yes & No & & \\
\hline \multicolumn{5}{|l|}{ Ethnicity } \\
\hline Amhara & 272 & 455 & 1.00 & 1.00 \\
\hline Tigray & 23 & 50 & $0.769(0.459,1.289)$ & $0.705(0.328,1.517)$ \\
\hline Kimant & 7 & 29 & $0.404(\mathbf{0 . 1 7 5}, \mathbf{0 . 9 3 4})$ & $0.627(0.075,1.947)$ \\
\hline Other & 4 & 2 & $3.346(0.609,18.38)$ & $1.092(0.142,8.401)$ \\
\hline \multicolumn{5}{|c|}{$\begin{array}{l}\text { Educational status } \\
\text { of father }\end{array}$} \\
\hline Illiterate & 44 & 68 & 1.00 & 1.00 \\
\hline Read \& write & 38 & 56 & $1.049(0.599,1.836)$ & $1.185(0.508,2.766)$ \\
\hline 1-6grade & 54 & 71 & $1.175(0.700,1.974)$ & $1.378(0.615,3.088)$ \\
\hline 7-12grade & 95 & 148 & $0.992(0.627,1.569)$ & $0.894(0.436,1.833)$ \\
\hline$>12$ grade & 75 & 193 & $0.601(\mathbf{0 . 3 7 8 , 0 . 9 5 5 )}$ & $0.369(\mathbf{0 . 1 7 0}, \mathbf{0 . 8 0 3})$ \\
\hline \multicolumn{5}{|l|}{ Economic status } \\
\hline$<28$ & 157 & 206 & 1.00 & 1.00 \\
\hline $29-56$ & 93 & 146 & $0.836(0.599,1.166)$ & $0.875(0.51,1.486)$ \\
\hline $57-84$ & 20 & 46 & $0.570(0.324,1.003)$ & $1.291(0.564,2.955)$ \\
\hline $85-112$ & 24 & 69 & $0.456(\mathbf{0 . 2 7 4 , 0 . 7 5 9 )}$ & $0.628(0.307,1.286)$ \\
\hline $113-167$ & 8 & 38 & $0.276(\mathbf{0 . 1 2 5 , 0 . 6 0 9 )}$ & $0.521(0.175,1.527)$ \\
\hline$>168$ & 4 & 31 & $0.169(\mathbf{0 . 0 5 9 , 0 . 4 9 0 )}$ & $0.059(\mathbf{0 . 0 0 8}, \mathbf{0 . 4 4 7})$ \\
\hline
\end{tabular}

\section{Snack frequency}

$\begin{array}{lllll}\text { Three/day } & 178 & 346 & 0.729(0.459,1.158) & 1.366(0.613,3.045) \\ \text { Twice/day } & 11 & 23 & 0.678(0.294,1.563 & 1.251(0.326,4.791) \\ \text { Once/day } & 81 & 116 & 0.989(0.0 .593,1.651) & 1.018(0.429,2.417) \\ \text { Occasional } & 36 & 51 & 1.00 & 1.00\end{array}$

Sweet foods and drinks

\begin{tabular}{lllll} 
Yes & 282 & 460 & $1.941(1.199,3.144)$ & $1.814(0.908,3.626)$ \\
No & 24 & 76 & 1.00 & 1.00 \\
Sugared coffee & & & & \\
Yes & 175 & 303 & 1.00 & 1.00 \\
No & 131 & 233 & $1.027(0.774,1.364)$ & $0.859(0.449,1.643)$ \\
Cleaning teeth & & & & \\
Yes & 120 & 357 & 1.00 & \\
No & 186 & 179 & $0.73(\mathbf{0 . 5 4}, \mathbf{0 . 9 7})$ & $0.077(\mathbf{0 . 0 3 0 - 0 . 2 0 1 )}$ \\
Rinsing mouth & & & & 1.00 \\
Yes & 260 & 49 & 1.00 & $0.399(\mathbf{0 . 1 9 8 - 0 . 8 0 4 )}$ \\
No & 46 & 40 & $0.46(\mathbf{0 . 2 9 1 , 0 . 7 1 5 )}$ & \\
Soft drinks & & & & 1.00 \\
Yes & 224 & 60 & 1.00 & $1.026(0.714,1.871)$ \\
\hline No & 82 & 476 & $21.67(14.98,31.34)$ &
\end{tabular}




\section{Conclusion}

Prevalence of dental caries was relatively higher and found public health problem. Lower socioeconomic status, lower father's educational level and poor oral hygiene practices were associated factors for children dental caries. Oral hygiene, dietary habits and access to dental care services are supreme important for the prevention of the problem.

\section{Competing interests}

The authors declare that they have no any conflict of interests.

\section{Authors' contribution}

FA wrote the proposal, participated in data collection, analyzed the data and drafted the paper. BW, KA and TA approved the proposal with some revisions, participated in data collection and analysis. All authors participated in the preparation of the manuscript and approved the final manuscript.

\section{Acknowledgement}

We would like to thank all parents and children who participated in the study. Our appreciation goes to the Gondar city Mayor and kebele administration offices for their assistance and permissions to conduct the research. Researchers are also highly indebted to thank University of Gondar referral hospital dentistry department for treatment of children and training data collectors.

\section{Author details}

${ }^{1}$ Public health specialist, Amhara National Regional State, Amhara, Ethiopia. 2Department of Epidemiology and Biostatistics, Institutes of Public Health, University of Gondar, P. O. Box 196, Gondar, Ethiopia. ${ }^{3}$ Department of Environmental and Occupational Health and Safety, Institutes of Public Health, University of Gondar, P. O. Box 196, Gondar, Ethiopia.

Received: 11 August 2012 Accepted: 15 January 2013

Published: 18 January 2013

\section{References}

1. Marsh PD: Are Dental Diseases Examples of Ecological Catastrophes? Microbiology 2003, 149:279-294.

2. World Health Organization: Prevention Methods and Program for Oral Diseases WHO Technical Report Series 713. Geneva: WHO; 1984.

3. Ritter AV: Dental Caries Talking with Patients. J Esthet Restor Dent 2004, $16: 76$.

4. Brodeur JM, Galarneau C: The High Incidence of Early Childhood Caries in Kindergarten-age Children. J College of Dentists of Quebec 2006, Supplement 6.

5. Hallett KB, O'Rourke PK: Pattern and severity of early childhood caries. Community Dent Oral Epidemiol 2006, 34:25-35.

6. Vered Y, Zini A, Livny A, Mann J, Sgan-Cohen H: Changing dental caries and periodontal disease patterns among a cohort of Ethiopian immigrants to Israel; 1999-2005. BMC Public Health 2008, 8:345.

7. El-Yazeed M, Rashed M, El Sayed M, Salah A: Dental Caries Prevalence among a group of Egyptian Nurseries Children. Life Sci J 2011, 8(1):512-519.

8. Amdemichael G: Prevalence and Determinant Factors of Dental Caries in Shashemene Woreda (MPH Thesis). Addis Ababa: University of Addis Ababa; 1995.

9. Okubagze J: Epidemiology of Dental Caries in a rural High land community North West Ethiopia; Ethiop. Med J 1987, 25:127.

10. Central Statistical Authority. Ethiopia: Population and Housing Census of Ethiopia. Addis Ababa; 2007.

11. FDRE population census commission: Summary and statistical report of the 2007 population and housing census. Addis Ababa: FDRE population census commission; 2008. Available from: CSA.

12. Masson LM, Blackburn GA, Sheehy C, Caig LC, Macdiamid JI, Holms BA, et al: Sugar intake and dental decay; results from a survey of children in Scotland. Br J Nutr 2010, 104:1555-1564.

13. Petersen P, Hoerup N, Poomviset N, Prommajan J, Watanapa A: Oral health status and oral health behavior of urban and rural school children in southern Thailand. Int Dent J 2001, 51:95-102.
14. Al-Jewair TS, Leake $J \mathrm{~L}$ : The prevalence and risks of early childhood caries in Toronto, Canada. J Contemp Dent Pract 2010, 11(5):1-8.

15. Tiano A, Moimaz S, Saliba O, Saliba N: Dental caries prevalence in children up to 36 months of age attending day care centers in municipalities with different water fluoride content. J Appl Oral Sci 2009, 17:1.

16. David J, Wang NJ, Astrom AN, Kuriakos S: Dental caries and associated factors in 12-year-old schoolchildren in Thiruvananthapuram, Kerrala, India. Int J Paediatric Dent 2005, 15(6):420-428.

doi:10.1186/1472-6831-13-7

Cite this article as: Ayele et al:: Predictors of Dental caries among children 7-14 years old in Northwest Ethiopia: a community based cross-sectional study. BMC Oral Health 2013 13:7.

\section{Submit your next manuscript to BioMed Central and take full advantage of:}

- Convenient online submission

- Thorough peer review

- No space constraints or color figure charges

- Immediate publication on acceptance

- Inclusion in PubMed, CAS, Scopus and Google Scholar

- Research which is freely available for redistribution 